\title{
Prevalence of podoconiosis and its associated factors in Gamo zone, Southern Ethiopia, 2021
}

Tamiru Getachew ${ }^{1 *}$ and Chuchu Churko ${ }^{2}$

\begin{abstract}
Background: Podoconiosis is a chronic non-infectious preventable disease. Though not fatal, it may cause social, economic and physical disability. Ethiopia is projected to bear one-fourth (25\%) of the global burden of podoconiosis. Despite its huge economic impact and chronic morbidity and disability, podoconiosis seems to be neglected. Therefore, the aim of this study was to assess the prevalence of podoconiosis and its associated factors in Gamo zone, Southern Ethiopia.
\end{abstract}

Methods: A community based cross sectional study was conducted among 683 household members. A multistage sampling method was used to select study participants. Binary logistic regression model was fitted to identify factors associated with podoconiosis. Odds ratio with 95\% confidence interval was computed to determine the level of significance; in multivariable analysis, variables with a $P$ value less than 0.05 were considered as statistically significant.

Results: The prevalence of podoconiosis was $6.2 \%$ (95\%Cl: $4.3-8 \%)$. The significantly contributed factors for the prevalence of podoconiosis were wealth index $(A O R=0.249,95 \% \mathrm{Cl}=0.073-0.845)$, number of shoes owned $(\mathrm{AOR}=$ $6.199,95 \% \mathrm{Cl}=1.281-29.98)$, times when individual do not wear shoes $(\mathrm{AOR}=2.448,95 \% \mathrm{Cl}=1.041-5.754)$, soap utilization during foot washing $(A O R=2.773,95 \% \mathrm{Cl}=1.210-6.355)$ and family history of leg swelling ( $A O R=4.69$, $95 \% \mathrm{Cl}=2.215-9.935)$.

Conclusions: This study showed that there was significant burden of podoconiosis in the study area. Wealth index, times when individual do not wear shoes, number of shoes owned, soap utilization during foot washing, and family history of leg swelling were significantly associated with podoconiosis. It is recommended to practice secondary prevention which includes regular foot hygiene and wearing shoes, and the use of antiseptic soaks.

Keywords: Podoconiosis, Disability, Neglected tropical diseases, Ethiopia

\section{Background}

Podoconiosis (endemic non-filarial elephantiasis) is a chronic non-infectious neglected tropical disease (NTD) which affects the lower limb. Although the causes of podoconiosis is not fully understood, current evidence

\footnotetext{
* Correspondence: tamdeme@gmail.com

'Department of Medical Anatomy, Arba Minch University, Southern Ethiopia, Ethiopia

Full list of author information is available at the end of the article
}

suggest that it is caused by longstanding exposure to red clay soil of volcanic origin [1]. Mineral particles, absorbed through the skin of the foot, are taken up into macrophages in the lower limb lymphatics and are thought to induce an inflammatory response in the lymphatic vessels, leading to fibrosis and obstruction of the vessel lumen [2].

The early symptoms of podoconiosis include itching of the skin of the forefoot and a burning sensation in the

C C The Author(s). 2022 Open Access This article is licensed under a Creative Commons Attribution 4.0 International License, which permits use, sharing, adaptation, distribution and reproduction in any medium or format, as long as you give appropriate credit to the original author(s) and the source, provide a link to the Creative Commons licence, and indicate if changes were made. The images or other third party material in this article are included in the article's Creative Commons licence, unless indicated otherwise in a credit line to the material. If material is not included in the article's Creative Commons licence and your intended use is not permitted by statutory regulation or exceeds the permitted use, you will need to obtain permission directly from the copyright holder. To view a copy of this licence, visit http://creativecommons.org/licenses/by/4.0/ The Creative Commons Public Domain Dedication waiver (http://creativecommons.org/publicdomain/zero/1.0/) applies to the data made available in this article, unless otherwise stated in a credit line to the data. 
foot and lower leg [3]. Later on it develops persistent swelling of the foot which starts from the dorsum of foot and gradually progress to the lower leg. The swelling is bilateral which is asymmetric and usually limited below the knees with mossy and nodular changes to the skin [4-6].

Podoconiosis is classified into five stages based on clinical characteristics; swelling limited below ankle and reversible overnight (stage I), swelling is not reversible, and when bumps and knobs are present and they remain below the level of the ankle (stage II), bumps and knobs are found above the level of the ankle (stage III), swelling extends above knee and not completely reversible overnight (stage IV) and joint fixation as a result of surrounding soft tissue overgrowth (stage V) [7].

Currently, podoconiosis does not have specific treatment, but primary prevention consist of avoidance of prolonged contact between the skin and irritant soils by robust footwear or covering of floor surfaces in areas of irritant soil, training in foot hygiene like washing the legs daily with soap and water, using antiseptics and emollients [8].

Although, podoconiosis is not fatal, affected individuals may show spoiled appearance of legs and the quality of life may be reduced $[9,10]$. Clinically, most patients acquire repeated infections of bacterial and fungal nature in the affected leg(s) necessitating extra medical attention. In addition the patients may experience acute adenolymphangitis (ALA) several times a year. It has been estimated that they lose an average of one month of economic activity every year due to morbidity [11]. In addition, people with podoconiosis may be stigmatized by being excluded from school, local meetings, churches, and barred from marriage with unaffected individuals [12].

The disease is widespread in tropical Africa, Central America and North India [13]. Evidence showed that one-sixth of the world's population, mostly in developing countries, is infected with one or more of the NTD (neglected tropical diseases). The World Health Organization (WHO) has identified seventeen NTDs for control and elimination at the global level [14] and among these diseases, eight were identified, including podoconiosis as priority in Ethiopia with a range of endemicity across the regions [15].

The national average prevalence was $4 \%$ with the highest prevalence in SNNPR(Southern Nations Nationality and People Regional) (8.3\%) followed by Oromia (4\%) and Amhara (3.9\%) regional states. Nationally, it is estimated that there are 1.56 million cases of podoconiosis and there were 345 districts with the prevalence of disease greater than $1 \%$ [16].

Despite its huge economic impact and chronic morbidity and disability $[10,11,17]$, podoconiosis seems to be neglected and not considered as public health problem in the study area. This study was the first in the area for assessing the prevalence and associated factors of podoconiosis.

\section{Methods and materials}

\section{Study setting and period}

This study was conducted in in Gamo zone, which is found in SNNPR, from January to February 2021. A community based cross sectional study was employed to assess prevalence of podoconiosis and its associated factors. Gamo zone is one of the administrative zones in southern Ethiopia. It is bordered by Wolayta, Dawro, and Gofa zones in the North, Lake Abaya in the northeast, and Amaro special woreda and Dirashe special woreda in the southeast, and South Omo in the southwest. The administrative center of the Gamo zone is Arba Minch town. Gamo zone has one administrative town and 18 woredas. Total population of the former Gamo gofa zone as to 2007 census was, 1, 593, 104, among which $49.8 \%(793,322)$ were males and $49.2 \%(799,782)$ were females. About,1,435,658(90.1\%) were rural dwellers [18].

\section{Study design and eligibility criteria}

A community based cross-sectional study design was employed. Those individuals whose age were 15 years old and above were eligible for this study and those individuals who were mentally handicapped and critically sick were excluded.

\section{Population}

All individuals living in Gamo zone whose age was 15 years and above were the source population. An individual with age 15 and above in purposively selected districts and who fulfilled the inclusion criteria were the study population.

\section{Sample size determination and sampling procedure}

The sample size was calculated using one population proportion formula of cross sectional study by considering the following assumptions: P (Prevalence of podoconiosis in Wolayta zone, Sodo zuria district 5.4\% [19], $\boldsymbol{\alpha}$ (level of significance) $=5 \%$, The Z-value at $95 \% \mathrm{CI}$ and $5 \% \boldsymbol{\alpha}= \pm 1.96$ (two tailed), Margin of error $(\mathrm{W})=2.5 \%$, power of study $=80 \%$. Then by using design effect of 2 and adding $10 \%$ non-response rate, the final sample size was 690 individuals from randomly selected household were included. A multi stage sampling method was applied. From administrative districts in Gamo zone, purposefully three districts were selected based on expert opinion for the presence of podoconiosis cases. After getting list of kebeles (smallest administrative units) from selected districts, couples of kebele per districts 
were selected by lottery method. Then, we took households list from selected kebele and feed to computer program Microsoft excel to select final participant households using computer driven random number by considering probability proportional to size (PPS) of households in the kebele.

Systematic selection of the households was done depending on the total number of households to the sample households required from each kebele by dividing the number of households in each kebele by sample size in that kebele. One participant was randomly selected from each household. On the other hand, in case there was no eligible subject in the selected household, the next immediate neighbor's household with eligible study subject was included in the study.

\section{Study variables \\ Dependent variables}

Presence or absence of podoconiosis.

\section{Independent variables}

Socidemographic variables: Age, sex, gender, educational level, marital status, ethnicity, religion, occupation, number of years lived in area, wealth index.

Shoe wearing and personal hygiene: age at the first shoe wearing, number of shoes owned, frequency of shoe wearing, utilization of soap during foot washing, average distance from water source to home.

\section{Data collection procedure and collection instrument}

Data was collected using interviewer administered structured questionnaire and observational check list. The questionnaire and observation check list were adapted and prepared from related literatures with modification to local context. It was prepared by English language and then translated to Amharic language and back to English language to ensure consistence. The questionnaire was sub-sectioned thematically to include: socidemographic characteristics, foot wearing and personal hygiene characteristics, knowledge about podoconiosis causes and prevention. Observational check list was utilized for clinical examination which contained diagnosis and staging of podoconiosis, assessment of ALA and measurement of leg circumference. Eight BSc nurses and health officers who had experience in diagnosing and treating the disease were recruited for data collection and three master degree holder were selected for supervision and trained for three days.

The researchers trained the nurses and the health officer on: the nature, etiology, treatment and prevention of podoconiosis, clinical features that differentiate podoconiosis from other diseases such as leprosy and filarial elephantiasis, assessment of ALA, assessment of presence of open wounds and mossy lesions.
Practical training was provided on clinical diagnosis of podoconiosis based on clinical algorithm for the diagnosis of podoconiosis for endemic areas [20], disease staging using a recently developed five level podoconiosis staging system [7] and the procedure for measuring of leg circumference [21].

The health extension workers and village chairpersons guided the interviewers during house-to-house visits. The nurses registered households that included a podoconiosis patient, administered a structured questionnaire to these patients, and conducted a physical examination of the legs and feet of patients. The legs and feet were assessed for clinical stage of disease. The largest circumference of the leg between the levels of the ankle and knee was measured using a tape to a precision level of the nearest centimeter. The study participants were asked to stand and the tape placed around the calf at the widest part between the lateral side of the ankle and knee as anatomical landmarks, and was ensured that the tape was horizontal around the calf and moved the tape up and down to locate the maximum circumference. Each data collector measured three times to the nearest $0.1 \mathrm{~cm}$ and finally the mean of three measurements was taken.

\section{Operational definitions \\ A person with podoconiosis}

An individual who has history of burning sensation in the feet when the swelling started; visible swelling that started at the feet and progressed upwards and with no known clinical signs or symptoms of leprosy or lymphatic filariasis [22].

\section{ALA}

A reddish hot, swollen leg with a painful groin [23].

\section{Leg circumference}

The largest circumference between the level of the ankle and the knee measured using a tape, to a precision level of the nearest centimeter [7].

\section{Mossy lesions}

Papillomatous horny lesions giving the skin a rough appearance [22].

\section{Criticality sick}

patients who could not respond to the interview due to medical illness [24].

\section{Data quality assurance}

Data cleaning was performed to assess completeness, consistence, outliers and missed values. Training was given for data collectors and supervisors. Pretest was conducted on $5 \%$ households outside of study kebele, 
necessary correction was made and questionnaire was further modified after a pretest. By taking $5 \%$ of the collected data randomly, the consistence was cross-checked based on the household code. If any error was identified during review, it would have been corrected accordingly by supervisors and investigators. Maximum effort was made to minimize inter observer bias during diagnosing presence of podoconiosis and measuring of leg circumference. Each data collectors measured the leg circumference three times and they took the average value of the three measurements to address intra-rater variation. During training session we have given practical training on leg circumference using pictures and animated videos to control inter-rater variation.

\section{Data processing and analysis}

After checking completeness of the collected data, data was transferred in to Microsoft excel for Windows 2010 and further transferred to SPSS software version 20 to make ready for data cleaning and analysis. Descriptive statistics was performed and presented by Mean $( \pm S D)$ for continuous normally distributed variables. Frequency and percentage, cross tabulation were performed for categorical predictors. Principal component analysis was performed to generate a wealth index. We used quintiles to categorize the wealth index. Binary logistic regression analysis was performed to see the independent effect of predictors on prevalence of podoconiosis. Bivariate logistic regression analysis was conducted to select potential candidates for the next step using $P$-value criteria of $\leq 0.25$.

Multivariable logistic regression analysis was performed to identify the independent effect of predictor's after controlling for potential confounders. Step wise back ward elimination model building procedure was done and model was compared by likely hood ratio test. Interaction and cofounder was tested and cutoff point was beta change greater than $20 \%$.

Multi colinearity was checked using variance inflation factor (VIF) and cutoff point was mean VIF $>10$ to have significant colinearity among predictors. Overall model fitness was checked by Hosmer and Leme show chisquare test; associations between prevalence of podoconiosis and predictors was summarized by using adjusted odds ratio and statistical significances was tested by Wald chi-square test at $95 \% \mathrm{CI}$ and $5 \%$ of $\alpha$.

\section{Results}

\section{Socio-demographic characteristics of participants}

Out of 690 participants, 683 households were interviewed making the response rate $99 \%$. Of 683 participants, $41 \%$ were male and $59 \%$ were female. The mean age $\left(\mathrm{SD}_{\underline{+}}\right)$ of the participant was $45.33 \pm 14.44$. On average, the respondents had lived in the study are for $32.19 \pm 19.94$ years. Half of the study participants $(n=$ $344,50.4 \%$ ) had no formal education (Table 1 ).

\section{Prevalence and clinical feature of podoconiosis}

The prevalence of podoconiosis in this study was found to be $6.2 \%$ (95\% CI: $4.3-8 \%$ ) (Fig. 1). The proportion among females was $(n=32,76.2 \%)$ and female to male ratio was 3.2:1. The average duration of illness between time of onset and time of interview was found to be $10.26 \pm 8.57$ days. The highest prevalence of podoconiosis, $(n=12,28.6 \%)$, was observed among age groups > 55 years. Mossy lesions and open wounds were observed in $(n=12,28.6 \%)$ and $(n=5,11.9 \%)$ of patients, respectively (Table 2). Among clinically diagnosed patients, $(n=19,46.6 \%)$ were identified in stage one, $(n=13$, $31.03 \%)$ in sage two and $(n=10,22.4 \%)$ stage three. More than half, $(n=6,60 \%)$ of affected male patients were in stage one (Fig. 2).

\section{ALA and coping strategies among podoconiosis patients}

On history and clinical examination about $(n=7,16.7 \%)$ patients had ALA at the time of interview. About $(n=$ $18,42.9 \%$ ) had episode of ALA in previous one year and $(n=7,16.7 \%)$ had ALA two weeks prior to the date of interview. The coping strategies adopted to reduce the morbidity during episodes of ALA were $(n=25,59.5 \%)$, stay in bed, $(n=20,38.1 \%)$ using antibiotics, $(n=17$, $40.5 \%)$ resort to less exertion and $(n=11,26.2 \%)$ using traditional herbs [Table 2].

\section{Shoe wearing and personal hygiene characteristics of the respondents}

All respondents were asked about their experience and attitudes towards footwear and personal hygiene, which are central to prevent, treat and control disease progression. The mean age of the participants $( \pm S D)$ when they had their first shoes wearing was $8.36 \pm$ 7.26 years old. Only about $(n=70,10.2 \%)$ of the participant did wear shoes during farming work and $(n=$ $425,62.2 \%)$ never walks bare foot. Regarding the frequency of feet washing, about $(n=656,96 \%)$ wash their feet daily. Nearly two fifth of the participants $(n=270,39.5 \%)$ did not use soap during feet washing. On observation more than three fourth $(n=513$, $75.1 \%)$ of participants had clean and intact feet, $(n=$ $139,20.4 \%$ and $(n=31,4.5 \%$ of participants had dirty and both dirty and cracked feet respectively (Table 3 ).

\section{Characteristics of knowledge related aspects}

Out of 683 participants, only $(n=232,34 \%)$ were heard about podoconiosis. From those who heard about the disease, nearly half $(n=84,46.4 \%)$ of the study participant reported that podoconiosis could be prevented by 
Table 1 Socio-demographic characteristics of participants in Gamo Zone, Southern Ethiopia, 2021 (n-683). (Others* include -NGO employee (0.1\%); daily laborer (2.8\%); jobless (1.3\%)

\begin{tabular}{|c|c|c|c|}
\hline Variable & Category & Frequency & Percentage \\
\hline \multirow[t]{5}{*}{ Age group } & $15-24$ & 46 & 6.7 \\
\hline & $25-34$ & 109 & 16.0 \\
\hline & $35-44$ & 167 & 24.5 \\
\hline & $45-54$ & 170 & 24.9 \\
\hline & $>55$ & 191 & 28.0 \\
\hline \multirow[t]{6}{*}{ Years lived in area } & $3-10$ years & 26 & 3.8 \\
\hline & $11-18$ years & 37 & 5.4 \\
\hline & 19-26 years & 78 & 11.4 \\
\hline & 27-36 years & 106 & 15.5 \\
\hline & $37-46$ years & 162 & 23.7 \\
\hline & $>47$ & 274 & 40.1 \\
\hline \multirow[t]{2}{*}{ Gender } & Male & 280 & 41 \\
\hline & Female & 403 & 59 \\
\hline \multirow[t]{5}{*}{ Education level } & No formal education & 344 & 50.4 \\
\hline & Able to read and write & 153 & 22.4 \\
\hline & Grade 1-8 & 94 & 13.8 \\
\hline & Grade 9-12 & 55 & 8.1 \\
\hline & More than secondary & 37 & 5.4 \\
\hline \multirow[t]{4}{*}{ Marital status } & Never married & 69 & 10.1 \\
\hline & Married & 564 & 82.6 \\
\hline & Widowed & 39 & 5.7 \\
\hline & Divorced & 11 & 1.6 \\
\hline \multirow[t]{3}{*}{ Ethnicity } & Gamo & 674 & 98.7 \\
\hline & Amhara & 8 & 1.2 \\
\hline & Wolayta & 1 & 1 \\
\hline \multirow[t]{6}{*}{ Occupation } & Farmer & 424 & 62.1 \\
\hline & Merchant & 44 & 6.4 \\
\hline & Student & 39 & 5.7 \\
\hline & Housewife & 115 & 16.8 \\
\hline & Government employee & 32 & 4.7 \\
\hline & Other* & 29 & 4.2 \\
\hline \multirow[t]{3}{*}{ Religion } & Protestant & 295 & 43.2 \\
\hline & Orthodox & 387 & 56.7 \\
\hline & Muslim & 1 & .1 \\
\hline \multirow[t]{2}{*}{ Monthly income } & $<500$ & 241 & 35.3 \\
\hline & $>=500$ & 442 & 64.7 \\
\hline \multirow[t]{5}{*}{ Wealth index quintile } & Lowest & 134 & 19.6 \\
\hline & Second & 145 & 21.2 \\
\hline & Middle & 200 & 29.3 \\
\hline & Fourth & 18 & 2.6 \\
\hline & Highest & 186 & 27.2 \\
\hline
\end{tabular}




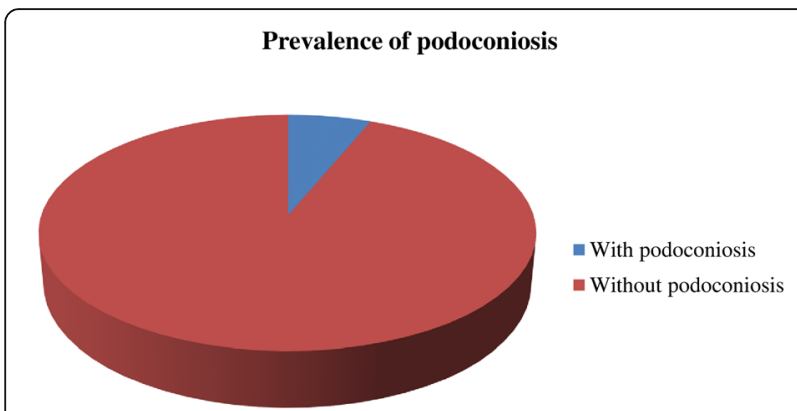

Fig. 1 Prevalence of podoconiosis in Gamo zone, Southern Ethiopia, 2021

wearing protective shoes whereas $15.9 \%$ said it is preventable by not marrying affected person. More than three fourth of the participants $(n=181,78 \%)$ said that podoconiosis is preventable (Table 4 ).

\section{Factors associated with podoconiosis}

Gender, marital status, wealth index, number of shoes owned, times when individual do not wear shoes, soap utilization during foot washing, family history of leg swelling, feet cleanness at time of interview, distance of water source from home, time taken to health facility were found associated with podoconiosis in bivariate analysis using $p$-values $<0.25$ cutoff.

In multivariable logistic regression analysis wealth index, number of shoes owned, times when individual do not wear shoes, soap utilization during foot washing and family history of leg swelling were significantly associated with podoconiosis.

In this study, those participants who had lowest wealth index were less likely to develop podoconiosis than those who had highest wealth index $(\mathrm{AOR}=0.249,95 \% \mathrm{CI}=$ $0.073,0.845, P<0.026)$. Podoconiosis among participants who did not wear shoes at home were about 2.5 times higher than as compared to those who never walked bare foot $(\mathrm{AOR}=2.448, \mathrm{CI}=1.041-5.754, P=0.04)$. The Odds of developing podoconiosis among those who did not use soap during foot washing nearly three times higher compared to those who did use soap during foot washing ( $\mathrm{AOR}=2.77,95 \% \mathrm{CI}=1.210-6.355, p=0.016$ ). Moreover, the odds of developing podoconiosis among those who had one pair of shoes were six times higher than to those who had more than three pairs of shoe$\mathrm{s}$. $(\mathrm{AOR}=6.19,95 \% \mathrm{CI}=1.281-29.98, P=0.023)$. The participants who had a family history of leg swelling was about five times more likely to develop podoconiosis than who had not family history of leg swelling (AOR = $4.669,95 \% \mathrm{CI}=2.215-9.935, P<0.001)$ (Table 5).

\section{Discussion}

This is the first community-based study attempted to assess the prevalence and factors associated with podoconiosis in Gamo zone, Southern Ethiopia. The present study showed that podoconiosis is a problem of public health importance.

The prevalence of podoconiosis in this study was $6.2 \%$ (95\% CI: 4.3-8\%).This findings is in line with the study conducted in Dano district, Ethiopia (6.3\%) [25]. This similarity might be due to the fact that the two populations have similar socio-demographic and life styles. On the contrary, this prevalence is high when compared to studies from Sodo zuria, southern Ethiopia (5.4\%) [19], Guliso district, west Ethiopia (2.8\%) [23], Wayu district, Ethiopia, 3.05\% [22] and Bedela Zuria of west Ethiopia, $5.6 \%$ [26]. Similarly, our finding was high as compared to studies from African countries like Kenya 3.4\% [27] and Cameron 0.5\% [28]. This difference might be due to podoconiosis prevention measures have been conducted more often than the current study area. In contrast, the finding of this study was low as compared to a study conducted in Midakegn district, Ethiopia (7.4\%) [29]. This discrepancy might be due the difference in intervention provision, accessibility of water and increasing awareness of shoes wearing practice of the participants.

A study conducted by Alemtsehay and his colleagues reported that a participant who had low wealth index was likely affected by podoconiosis than participants who had high wealth index [23,30]. Surprisingly, in our study the participants who had low wealth index were less likely affected by podoconiosis than participants who had highest wealth index. The possible reason could be participants who had high wealth index might be genetically more susceptible to develop podoconiosis than participants who had low wealth index. However, this variable needs to be studied further.

The current study showed that shoes wearing practice was associated with developing of podoconiosis. The participants who did not wear shoes at home were about 2.5 times higher chance of being affected by podoconiosis as compared to those who never walk bare foot $(\mathrm{AOR}=2.448, \mathrm{CI}: 1.041-5.754)$. This agreed with the previous studies [25, 27]. This is due to as majority of the participant's the floor of the house made from earth this soil particles enter in to the skin of uncovered feet. A long term exposure to soil particles stimulates a provocative reaction in the lymphatic system which causes thickening and obstruction of lymphatic system [31].

Podoconiosis among individuals who had one pair of shoes were six times significantly higher than those who had more than three pairs of shoes (AOR $=6.19,95 \% \mathrm{CI}$ : 1.281-29.98). This is because having more shoes will improve the frequency of shoes wearing practice. This will reduce exposure to the irritant soil which is believed to be a cause of podoconiosis.

The odds of developing podoconiosis among those who did not use soap during foot washing were three 
Table 2 Clinical feature of podoconiosis and ALA in Gamo Zone, Southern Ethiopia, 2021

\begin{tabular}{|c|c|c|c|}
\hline Variable & Category & Frequency & Percent \\
\hline \multirow[t]{2}{*}{ Sex } & Male & 10 & 23.8 \\
\hline & Female & 32 & 76.2 \\
\hline \multirow[t]{5}{*}{ Age category } & $15-24$ & 4 & 9.5 \\
\hline & $25-34$ & 7 & 16.6 \\
\hline & $35-44$ & 9 & 21.4 \\
\hline & $45-54$ & 10 & 23.8 \\
\hline & $>55$ & 12 & 28.6 \\
\hline \multirow[t]{3}{*}{ Staging of the diseases } & Stage one & 19 & 45.2 \\
\hline & Stage two & 13 & 31 \\
\hline & Stage three & 10 & 23.8 \\
\hline \multirow[t]{2}{*}{ Sought treatment } & Yes & 12 & 28.6 \\
\hline & No & 30 & 71.4 \\
\hline \multirow[t]{2}{*}{ Treatment site } & Traditional healers & 5 & 41.7 \\
\hline & Health institution & 7 & 58.3 \\
\hline \multirow[t]{2}{*}{ Mossy lesion } & Present & 12 & 28.6 \\
\hline & Absent & 30 & 71.4 \\
\hline \multirow[t]{2}{*}{ Open wound } & Present & 5 & 11.9 \\
\hline & Absent & 37 & 88.1 \\
\hline \multirow[t]{5}{*}{ Right leg circumference } & $<21$ & 6 & 13.9 \\
\hline & $21-25$ & 7 & 16.7 \\
\hline & $26-36$ & 12 & 28.6 \\
\hline & $37-47$ & 7 & 16.7 \\
\hline & $>47$ & 10 & 23.8 \\
\hline \multirow[t]{5}{*}{ Left leg circumference } & $<21$ & 5 & 11.9 \\
\hline & $21-25$ & 9 & 21.4 \\
\hline & $26-36$ & 10 & 23.8 \\
\hline & $37-47$ & 5 & 11.9 \\
\hline & $>47$ & 13 & 30.9 \\
\hline \multirow[t]{2}{*}{ ALA at the time of interview } & Present & 27 & 16.7 \\
\hline & Absent & 35 & 83.3 \\
\hline \multirow[t]{4}{*}{ Last time the patient had ALA } & Last 2 weeks & 7 & 16.7 \\
\hline & Last 1 month & 6 & 14.3 \\
\hline & Last 6 months & 11 & 26.2 \\
\hline & Beyond 1 year & 18 & 42.9 \\
\hline \multirow[t]{2}{*}{ Sought treatment for ALA } & Yes & 12 & 71.4 \\
\hline & No & 30 & 28.6 \\
\hline \multirow[t]{3}{*}{ Season when symptoms of ALA get worse } & Rainy and wet season & 19 & 45.2 \\
\hline & Hot and dry season & 13 & 31 \\
\hline & No specific season & 10 & 23.8 \\
\hline \multirow[t]{5}{*}{ Coping mechanism for ALA $(n=42)$} & Using antibiotics & 20 & 47.6 \\
\hline & Washing feet & 22 & 52.4 \\
\hline & Stay in bed & 25 & 59.5 \\
\hline & Resort to less exertion & 17 & 40.5 \\
\hline & Using traditional herbs & 11 & 26.2 \\
\hline \multirow[t]{4}{*}{ Precipitating factors } & Long walks & 19 & 45.2 \\
\hline & Mitch & 18 & 42.9 \\
\hline & Laborious work & 20 & 47.6 \\
\hline & Dust & 24 & 57.1 \\
\hline
\end{tabular}




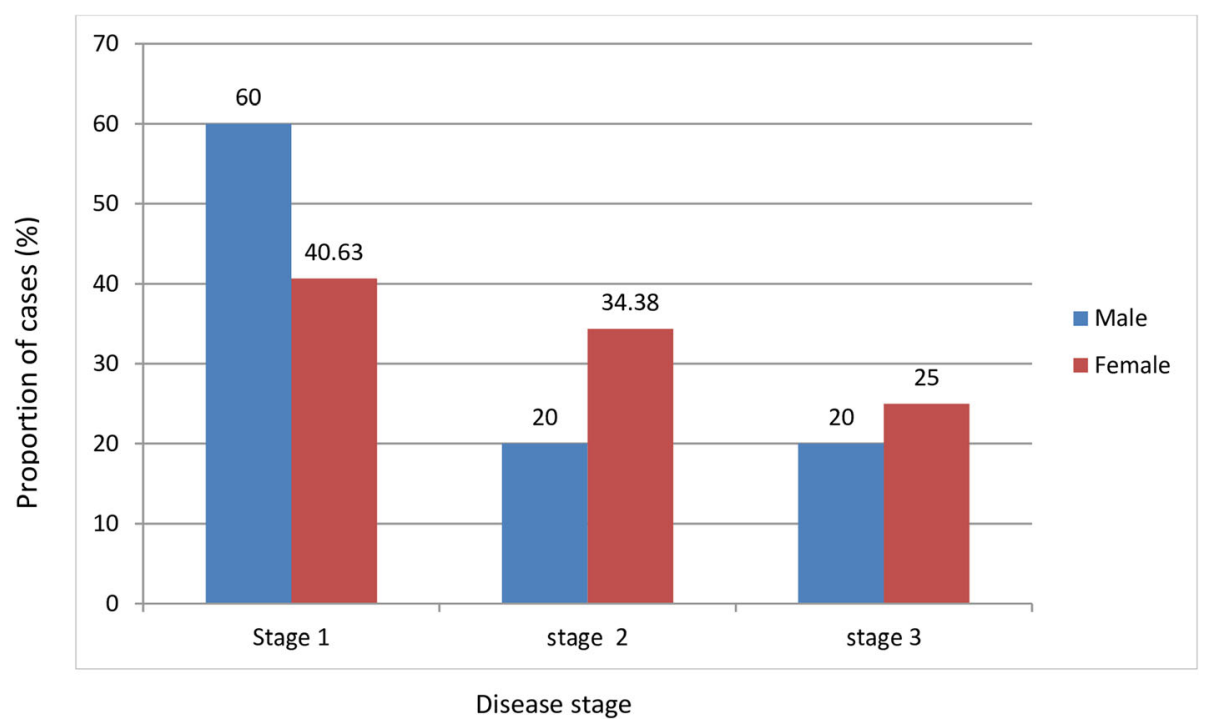

Fig. 2 Clinical stages of podoconiosis among female and male patient in Gamo zone, Southern Ethiopia, 2021

Table 3 Foot wearing and personal hygiene related characteristics of the participants, Gamo Zone, Southern Ethiopia, 2021

\begin{tabular}{|c|c|c|c|}
\hline Characteristics & Category & Frequency & Percentage \\
\hline Average age of first shoes wearing & Mean (SD) & $8.36 \pm 7.26$ years & \\
\hline \multirow[t]{4}{*}{ Number of pairs of shoes owned } & One pair & 167 & 24.5 \\
\hline & Two pairs & 269 & 39.4 \\
\hline & Three pairs & 171 & 25.0 \\
\hline & More than three pairs & 76 & 11.1 \\
\hline \multirow[t]{4}{*}{ Type of shoe worn during the interview } & Not footwear & 53 & 7.8 \\
\hline & Hard plastics & 354 & 51.8 \\
\hline & Canavas & 223 & 32.7 \\
\hline & Open sandal & 53 & 7.8 \\
\hline \multirow[t]{4}{*}{ Times when individuals do not wear shoes } & During farming work & 70 & 10.2 \\
\hline & During non-farming work & 49 & 7.2 \\
\hline & at home & 139 & 20.4 \\
\hline & never walks bare foot & 425 & 62.2 \\
\hline \multirow[t]{3}{*}{ Feet cleanliness at the time of interview } & Intact feet & 513 & 75.1 \\
\hline & Dirty feet & 139 & 20.4 \\
\hline & Both dirty and cracked feet & 31 & 4.5 \\
\hline \multirow[t]{2}{*}{ Frequency of foot washing } & Daily & 656 & 96.0 \\
\hline & Two to three times per week & 27 & 4.0 \\
\hline \multirow[t]{2}{*}{ Use soap for washing } & Yes & 413 & 60.5 \\
\hline & No & 270 & 39.5 \\
\hline \multirow[t]{4}{*}{ Source of water } & Pipe & 490 & 71.7 \\
\hline & Borehole or well & 96 & 14.1 \\
\hline & River or stream & 78 & 11.4 \\
\hline & Pond or stagnant & 19 & 2.8 \\
\hline \multirow[t]{2}{*}{ Average distance from water source to home } & Near home (less than $30 \mathrm{~min}$ ) & 329 & 48.2 \\
\hline & Far away from home (more than $30 \mathrm{~min}$ ) & 354 & 51.8 \\
\hline \multirow[t]{2}{*}{ Types of floor in your household } & Earth & 517 & 75.7 \\
\hline & Non-earth & 166 & 24.3 \\
\hline \multirow[t]{3}{*}{ Types of toilet facility } & Pit latrine without slab/open pit & 511 & 74.8 \\
\hline & Pit latrine with slab & 139 & 20.4 \\
\hline & No facility/bush field & 33 & 4.8 \\
\hline
\end{tabular}


Table 4 Knowledge related aspects among people with and without podoconiosis in Gamo zone, Southern Ethiopia, 2021

\begin{tabular}{|c|c|c|c|}
\hline \multirow[t]{2}{*}{ Variables } & \multirow[t]{2}{*}{ Category } & \multicolumn{2}{|c|}{ Podoconiosis status } \\
\hline & & Yes & No \\
\hline \multirow[t]{2}{*}{ Heard of podoconiosis } & Yes & 15(35.7\%) & $211(32.9 \%)$ \\
\hline & No & $27(64.3 \%)$ & $430(67.1 \%)$ \\
\hline \multirow[t]{6}{*}{ Cause of podoconiosis } & Soil particles & $7(25 \%)$ & 68(33.3\%) \\
\hline & Poverty & $6(21.4 \%)$ & $45(22.1 \%)$ \\
\hline & Malnutrition & $7(25 \%)$ & $30(14.7 \%)$ \\
\hline & Devil spirit & $4(14.3 \%)$ & $15(7.4 \%)$ \\
\hline & Hereditary & $4(14.3 \%)$ & $14(6.9 \%)$ \\
\hline & Snake bite & 0 & $32(15.7 \%)$ \\
\hline \multirow[t]{2}{*}{ Podonconsis is preventable } & Yes & $22(78.6 \%)$ & 159(77.9\%) \\
\hline & No & $6(21.4 \%)$ & $45(22.1 \%)$ \\
\hline \multirow[t]{4}{*}{ Methods of podonconsis prevention } & Wearing protective shoes & $11(50 \%)$ & $73(45.9 \%)$ \\
\hline & Washing feet frequently & $4(18.2 \%)$ & $52(32.7 \%)$ \\
\hline & Avoiding marriage with affected person & $4(18.2 \%)$ & $25(15.7 \%)$ \\
\hline & Avoid with working cold air & $3(13.6 \%)$ & $9(5.7 \%)$ \\
\hline \multirow[t]{2}{*}{ Podonconsis curable } & Yes & $18(64.3 \%)$ & 108(52.9\%) \\
\hline & No & 10(35.7\%) & $96(47.1 \%)$ \\
\hline \multirow[t]{2}{*}{ Podonconsis transmits from person to person } & Yes & $12(42.9 \%)$ & $73(35.8 \%)$ \\
\hline & No & $16(57.1 \%)$ & $131(64.2 \%)$ \\
\hline
\end{tabular}

times higher than those who utilized soap (AOR = 2.77,95\%CI: 1.210-6.355). This is consistent with the study conducted by Dejene and his colleagues in central Ethiopia [25] and in Sodo zuria, Southern Ethiopia [30]. This is because washing foot with soap removes soil particles that triggers the diseases process and prevent infection.

A study conducted on a topical model for gene -environment interaction showed a strong genetic component, the sibling of an affected person is at five times increased risk of developing podoconiosis when compared with a person in the general population [13]. Similarly, in our study the participants who had a family history of leg welling is about five times more likely to develop podoconiosis than who had no family history of leg swelling. (AOR $=4.67,95 \% \mathrm{CI}(2.22-9.94)$. This is might be due to the effect of genes in the development of podoconiosis; this result still requires further genetic analysis.

In the present study majority of patients were in the early stage of podoconiosis (Stage I and Stage II). This agreed with a study conducted in Dana district and Jeldu district west shoea, Ethiopia [25, 32]. Since most cases of podoconiosis in present study were in early stage of disease, secondary prevention is potentially helps to control the diseases progression. A study conducted in southern Ethiopia showed that a reduction in leg circumference and an improvement in clinical stage were observed following the use of simple lymphedema management method including regular wearing of shoes, frequent washing of foot with soap and water and utilizing bandage [33].

\section{Strength and limitation of the study}

As strength this study was the first study in the area to assess the prevalence and associated factors of podoconiosis. The study is not without limitation. Firstly, it is likely to face issues of non-response bias due to stigma families may hide affected members. We attempted to minimize undercounting by using health extension workers as data collectors. They are familiar, trusted community members who know most families in their kebeles. Secondly, we used a clinical algorithm to differentiate podoconiosis from other disease causing leg swelling. If serological test was used, it would have helped to exclude it from lymphatic filariasis. However, given that the study area is found at high elevation above sea level, transmission of filarial is extremely unlikely. Thirdly, even if we estimated the prevalence of podoconiosis we could not able to generalize the findings to Gamo zone as the districts were selected purposively.

\section{Conclusion and recommendation}

This study reported a high prevalence of podoconiosis and its associated factors in the study area. Number of shoes owned, wealth index, times when individual do not wear shoes, family history of leg swelling, soap 
Table 5 Factors associated with podoconiosis among people who are living in Gamo zone, Southern Ethiopia, 2021

\begin{tabular}{|c|c|c|c|c|c|c|}
\hline \multirow[t]{2}{*}{ Variable } & \multirow[t]{2}{*}{ Category } & \multicolumn{2}{|c|}{ Podoconiosis } & \multirow[t]{2}{*}{$\operatorname{COR}(95 \% \mathrm{Cl})$} & \multirow[t]{2}{*}{ AOR(95\%Cl) } & \multirow{2}{*}{$\begin{array}{l}p \text { - } \\
\text { value }\end{array}$} \\
\hline & & Yes & No & & & \\
\hline \multirow[t]{2}{*}{ Gender } & Male & 10 & 270 & 1 & & \\
\hline & Female & 32 & 371 & $0.429(0.208-0.889)$ & $0.5250 .240,1.145$ & 0.105 \\
\hline \multirow[t]{4}{*}{ Marital status } & Never married & 7 & 62 & 1 & 1 & \\
\hline & Married & 32 & 532 & $0.533(226,1.258)$ & $0.487(0.153,1.547)$ & 0.223 \\
\hline & Widowed & 2 & 37 & $0.479(094,2.427)$ & $0.194(0.029,1.297)$ & 0.091 \\
\hline & Divorced & 1 & 10 & $0.886(098,7.987)$ & $0.8610 .077,9.615$ & 0.903 \\
\hline \multirow[t]{5}{*}{ Wealth index (quintiles) } & Lowest & 5 & 129 & $0.617(0.209,0.381)$ & $0.249(0.073,0.845)$ & $0.026^{*}$ \\
\hline & Second & 6 & 139 & $0.687(0.248,0.470)$ & $0.607(0.204,1.807)$ & 0.370 \\
\hline & Middle & 17 & 183 & $1.478(0.673,0.330)$ & $1.416(0.594,3.377)$ & 0.433 \\
\hline & Fourth & 3 & 15 & $3.182(0.800,0.100)$ & $2.765(0.578,13.231)$ & 0.203 \\
\hline & Highest & 11 & 175 & 1 & 1 & \\
\hline \multirow[t]{4}{*}{ Number of shoes owned } & One pair & 20 & 147 & $7.45(1.72-32.16)$ & $6.199(1.281,29.98)$ & $0.023^{*}$ \\
\hline & Two pairs & 9 & 260 & $0.7(0.133-3.68)$ & $1.678(0.325,8.669)$ & 0.537 \\
\hline & Three pairs & 11 & 160 & $1.57(0.32-7.79)$ & $3.508(0.693,17.76)$ & 0.129 \\
\hline & More than three pairs & 2 & 74 & 1 & 1 & \\
\hline \multirow[t]{4}{*}{ Types of foot wear at time of interview } & not footwear & 7 & 46 & $1.461(0.433,4.932)$ & $0.977(0.237,4.023)$ & 0.975 \\
\hline & hard plastics & 22 & 332 & $0.636(0.230-1.759)$ & $0.859(0.251,2.933)$ & 0.808 \\
\hline & canavas & 8 & 215 & $0.357(0.112-1.140)$ & $0.421(0.106,1.675)$ & 0.219 \\
\hline & open sandal & 5 & 46 & 1 & & \\
\hline \multirow[t]{4}{*}{ Times when individual do not wear shoes } & During farming work & 7 & 63 & $2.374(0.959,5.877)$ & $1.461(0.499,4.280)$ & 0.490 \\
\hline & During non-farming work & 3 & 46 & $1.394(0.397-4.890)$ & $1.092(0.268,4.452)$ & 0.903 \\
\hline & at home & 13 & 126 & $2.205(1.059-4.590)$ & $2.448(1.041,5.754)$ & $0.040^{*}$ \\
\hline & never walks bare foot & 19 & 406 & 1 & 1 & \\
\hline \multirow[t]{2}{*}{ Soap using during foot washing } & Yes & 20 & 393 & 1 & & \\
\hline & No & 22 & 248 & $1.74(0.932,3.26)$ & $2.773(1.210,6.355)$ & $0.016^{*}$ \\
\hline \multirow[t]{2}{*}{ Family history of leg swelling } & yes & 18 & 89 & $4.652(2.426,8.918)$ & $4.69(2.215,9.935)$ & $0.000^{*}$ \\
\hline & No & 24 & 552 & 1 & & \\
\hline \multirow[t]{3}{*}{ Feet cleanness at time of interview } & Clean and intact feet & 26 & 487 & 1 & 1 & \\
\hline & Dirty feet & 14 & 125 & $2.09(1.064,4.136)$ & $0.353(0.996,5.557)$ & 0.051 \\
\hline & Both dirty and cracked feet & 2 & 29 & $1.29(0.292,5.710)$ & $1.741(0.324,9.362)$ & 0.518 \\
\hline \multirow[t]{2}{*}{ Distance of water source } & Near home (less than $30 \mathrm{~min}$ ) & & & 1 & 1 & \\
\hline & More than $30 \mathrm{~min}$ & & & $0.681(0.362-1.27)$ & $0.705(0.3231 .541)$ & 0.381 \\
\hline \multirow[t]{2}{*}{ Time taken to heath facility } & $<1.5 \mathrm{~h}$ & 21 & 416 & 1 & & \\
\hline & $>1.5 \mathrm{~h}$ & 21 & 225 & $1.84(0.98,3.5)$ & $1.409(0.689,2.87)$ & 0.347 \\
\hline
\end{tabular}

utilization during foot washing were found associated with development of podoconiosis.

As majority of the patient were in early stage of the disease. It is recommended to practice secondary prevention which includes regular foot hygiene and wearing shoes. Health education shall be given for increasing protective shoe wearing practice, improving personal hygiene and treatment seeking behavior. Governmental and non-governmental organization should work by integrating existing health programs addressing water and sanitation and neglected tropical disease. Podoconiosis treatment and rehabilitation center shall be established.

\section{Abbreviation}

ALA: Acute adenolymphangitis; NTD: Neglected Tropical Disease; SNNP R: Southern Nations Nationality and People Regional State; VIF: Variance Inflation Factor; WHO: World Health Organization

\section{Acknowledgments}

We would like to extend our gratitude to Arba Minch University, College of Medicine and Health Science, Center for Neglected and Tropical Disease office for funding this research project. We express our sincere gratitude and 
appreciation to data collectors and supervisors. Lastly, we would like to thank zonal and districts health officials who were helping us in facilitating the data collection.

\section{Authors' contributions}

TG contributed to conception and design of the study, analysis of data, and writing of the paper.TG took part in the design, data analysis, and writing of the paper. TG and CC are involved in the study from the initial inception to the final approval of the paper. In addition, CC is involved in paper writing and updated it to this standard of the publication. All authors read and approved the final manuscript.

\section{Funding}

This study was fully funded by Arba Minch University.

\section{Availability of data and materials}

The datasets for the current study are not publicly available but are available upon reasonable request by emailing the corresponding author.

\section{Declarations}

\section{Ethical approval and consent to participate}

Ethical approval obtained from Arba Minch University institutional ethical review board with the reference No IRB/214/12. Letter of permission to undertake the study was secured from Gamo zone health department, respective districts and kebeles. Informed oral consent was taken from an individual participant. Consent was obtained from parents or guardians for participates whose age was less than 18 years and assent was taken from each participants. Confidentiality of participant information was ensured. People with podoconiosis were advised to attend health facilities for management of the condition.

\section{Consent for publication}

Not applicable.

\section{Competing interests}

The authors declare that they have no competing interests.

\section{Author details}

${ }^{1}$ Department of Medical Anatomy, Arba Minch University, Southern Ethiopia, Ethiopia. ${ }^{2}$ Collaborative Research and Training Center for Neglected Tropical Disease, Arba Minch University, Southern Ethiopia, Ethiopia.

Received: 13 August 2021 Accepted: 2 February 2022

Published online: 10 February 2022

\section{References}

1. World Health Organization. Podoconiosis: endemic non-filarial elephantiasis. 2018.

2. Deribe K, Davey G. How 'the association of endemic elephantiasis of the lower legs in East Africa with soil derived from volcanic rocks' has underpinned progress in podoconiosis research. Trans R Soc Trop Med Hyg. 2014;108(9):528-9. https://doi.org/10.1093/trstmh/tru112.

3. Davey G. Podoconiosis, non-filarial elephantiasis, and lymphology. Lymphology. 2010;43(4):168-77.

4. Price E, McHardy W, Pooley F. Endemic elephantiasis of the lower legs as a health hazard of barefooted agriculturalists in Cameroon, West Africa. Ann Occup Hyg. 1981;24(1):1-8.

5. Mousley E, Deribe K, Tamiru A, Davey G. The impact of podoconiosis on quality of life in northern Ethiopia. Health Qual Life Outcomes 2013;11(1):111, https://doi.org/10.1186/1477-7525-11-122.

6. Fuller LC. Podoconiosis: endemic nonfilarial elephantiasis. Curr Opin Infect Dis. 2005;18(2):119-22. https://doi.org/10.1097/01.qco.0000160899.64190.15.

7. Tekola F, Ayele Z, Mariam DH, Fuller C, Davey G. Development and testing of a de novo clinical staging system for podoconiosis (endemic non-filarial elephantiasis). Tropical Med Int Health. 2008;13(10):1277-83. https://doi. org/10.1111/j.1365-3156.2008.02133.x.

8. Tekola-Ayele F, Yeshanehe WE. Podoconiosis: tropical lymphedema of the lower legs. Dermatology and Allergology-Principles and Practice, vol. 14. 1st ed. Hong Kong: iConcept Press Ltd; 2014.
9. van 't Noordende AT, Aycheh MW, Schippers A. The impact of leprosy, podoconiosis and lymphatic filariasis on family quality of life: A qualitative study in Northwest Ethiopia. PLoS Neglected Trop Dis. 2020;14(3):e0008173.

10. WHO. Accelerating work to overcome the global impact of neglected tropical diseases: a roadmap for implementation: World Health Organization; 2012.

11. Deribe K, Tomczyk S, Tekola-Ayele F. Ten years of podoconiosis research in Ethiopia. PLoS Negl Trop Dis. 2013;7(10).

12. GebreHanna E. The social burden of podoconiosis and familial occurrence in its development. MPH Thesis, Addis Ababa University; 2005.

13. Davey G, GebreHanna E, Adeyemo A, Rotimi C, Newport M, Desta K. Podoconiosis: a tropical model for gene-environment interactions? Trans $R$ Soc Trop Med Hyg. 2007;101(1):91-6. https://doi.org/10.1016/j.trstmh.2006. 05.002.

14. Mitra AK, Mawson AR. Neglected tropical diseases: epidemiology and global burden. Trop Med infect Dis. 2017;2(3):36. https://doi.org/10.3390/tropica Imed2030036.

15. Ababa A. Federal democratic republic of Ethiopia ministry of health. Postnatal Care: Ethiopia; 2003.

16. Ethiopian Federal Misitry of Health. National Neglected Tropical Diseases Master Plan 2015/16-2019/20; 2016. p. 57-8.

17. Burn H, Aweke S, Wondie T, Habtamu E, Deribe K, Rajak S, et al. Podoconiosis, trachomatous trichiasis and cataract in northern Ethiopia: A comparative cross sectional study. PLoS Negl Trop Dis. 2017;11(2):e0005388.

18. Central Statistical Agency MPC. Population and Housing Census. 2007. https://microdata.worldbank.org/index.php/catalog/related-materials. Accessed 23 Dec 2021

19. Elias A. Prevalence of podoconisis and associated factors in Sodo Zuria. ACIP H: Wolayta Zone, South Ethiopia; 2015.

20. Deribe K, Florence L, Kelemework A, Getaneh T, Tsegay G, Cano J, et al. Developing and validating a clinical algorithm for the diagnosis of podoconiosis. Trans R Soc Trop Med Hyg. 2020;114(12):916-25. https://doi. org/10.1093/trstmh/traa074.

21. Southampton N, Centre BR. National institute for health research. 2017. https://www.uhs.nhs.uk/Media/Southampton-Clinical-Research/Procedures/ BRCProcedures/Procedure-for-adult-circumference-measurements.pdf. Accessed 23 Dec 2021.

22. Bekele K, Deribe K, Amberbir T, Tadele G, Davey G, Samuel A. Burden assessment of podoconiosis in Wayu Tuka woreda, east Wollega zone, western Ethiopia: a community-based cross-sectional study. BMJ Open. 2016;6(9):e012308. https://doi.org/10.1136/bmjopen-2016-012308.

23. Alemu G, Tekola Ayele F, Daniel T, Ahrens C, Davey G. Burden of podoconiosis in poor rural communities in Gulliso woreda, West Ethiopia. PLoS Negl Trop Dis. 2011;5(6).

24. Deribe K, Mbituyumuremyi A, Cano J, Bosco MJ, Giorgi E, Ruberanziza E, et al. Geographical distribution and prevalence of podoconiosis in Rwanda: a cross-sectional country-wide survey. Lancet Glob Health. 2019;7(5):e671e80. https://doi.org/10.1016/S2214-109X(19)30072-5.

25. Dejene $\mathrm{F}$, Merga $\mathrm{H}$, Asefa $\mathrm{H}$. Community based cross sectional study of podoconiosis and associated factors in Dano district, Central Ethiopia. PLoS Negl Trop Dis. 2019;13(1):e0007050. https://doi.org/10.1371/journal.pntd. 0007050.

26. Tekola Ayele F, Alemu G, Davey G, Ahrens C. Community-based survey of podoconiosis in Bedele Zuria woreda, West Ethiopia. Int Health. 2013;5(2): 119-25. https://doi.org/10.1093/inthealth/iht003.

27. Muli J, Gachohi J, Kagai J. Soil iron and aluminium concentrations and feet hygiene as possible predictors of Podoconiosis occurrence in Kenya. PLoS Negl Trop Dis. 2017;11(8):e0005864. https://doi.org/10.1371/journal.pntd. 0005864.

28. Deribe K, Beng AA, Cano J, Njouendo AJ, Fru-Cho J, Awah AR, et al. Mapping the geographical distribution of podoconiosis in Cameroon using parasitological, serological, and clinical evidence to exclude other causes of lymphedema. PLoS Negl Trop Dis. 2018;12(1):e0006126. https://doi.org/10.13 71/journal.pntd.0006126.

29. Geshere Oli G, Tekola Ayele F, Petros B. Parasitological, serological and clinical evidence for high prevalence of podoconiosis (non-filarial elephantiasis) in Midakegn district, Central Ethiopia. Tropical Med Int Health. 2012;17(6):722-6. https://doi.org/10.1111/j.1365-3156.2012.02978.x.

30. Elias A, Yemane $H$, Meskele M. Podoconiosis prevalence and its associated factors in soddo zuria district, Wolaita zone, south Ethiopia. J Pharm Altern Med. 2016;13:48-56. 
31. Davey G, Burridge E. Community-based control of a neglected tropical disease: the mossy foot treatment and prevention association. PLoS Negl Trop Dis. 2009;3(5):e424. https://doi.org/10.1371/journal.pntd.0000424.

32. Negasa A, Dufera M. Assessment of etiology of elephantiasis and its associated risk factors in Jeldu District, west Shoa. Ethiopia J Trop Med. 2021;2021:1-8. https://doi.org/10.1155/2021/5551637.

33. Sikorski C, Ashine M, Zeleke Z, Davey G. Effectiveness of a simple lymphoedema treatment regimen in podoconiosis management in southern Ethiopia: one year follow-up. PLoS Negl Trop Dis. 2010;4(11):e902. https://doi.org/10.1371/journal.pntd.0000902.

\section{Publisher's Note}

Springer Nature remains neutral with regard to jurisdictional claims in published maps and institutional affiliations.

Ready to submit your research? Choose BMC and benefit from:

- fast, convenient online submission

- thorough peer review by experienced researchers in your field

- rapid publication on acceptance

- support for research data, including large and complex data types

- gold Open Access which fosters wider collaboration and increased citations

- maximum visibility for your research: over $100 \mathrm{M}$ website views per year

At BMC, research is always in progress.

Learn more biomedcentral.com/submissions 